Research Journal of Applied Sciences, Engineering and Technology 7(5): 1012-1016, 2014

DOI:10.19026/rjaset.7.351

ISSN: 2040-7459; e-ISSN: 2040-7467

(C) 2014 Maxwell Scientific Publication Corp.

Submitted: January 31, $2013 \quad$ Accepted: February 25, $2013 \quad$ Published: February 05, 2014

Research Article

\title{
Microstructure Evolution of Multi-Heat Forging and Numerical Simulation for 316LN Steel
}

\author{
Duan Xing-Wang, Chen Hui-Qin and Liu Jian-Sheng \\ College of Materials Science and Engineering, Taiyuan University of \\ Science and Technology, Taiyuan 030024, China
}

\begin{abstract}
Microstructure evolution has been studied by multi-heat forging experiments and numerical simulation in order to determine the reasonable forging technology of $316 \mathrm{LN}$ steel. The microstructure evolution models were obtained by hot compressive tests and heat treatment tests of $316 \mathrm{LN}$ steels. The one-heat and three-heat upsetting experiments were carried on. Meanwhile, the corresponding numerical simulations were performed. The results show that, the grain uniformity of three-heat upsetting is much better that of one-heat upsetting. The average grain size of three-heat upsetting is smaller than that of one-heat upsetting. So, the forging technology of multi-heat and little deformation should be adopted for $316 \mathrm{LN}$ steel forging. By comparing experimental average grain sizes with simulated average grain sizes for three-heat upsetting, it is found that the simulated values are in agreement with experimental values, which shows that the numerical simulation can be employed to predict the forging microstructure evolution of 316 LN steel.
\end{abstract}

Keywords: 316 LN, microstructure evolution, multi-heat forging, numerical simulation, re-crystallization

\section{INTRODUCTION}

In recent years, the microstructure evolution of the metals and alloys in hot forming process is a hot problem. Many studies have been carried out to predict the microstructure evolution during forging process (Cho et al., 2005; Ma et al., 2007; Lin and Chen, 2009; He et al., 2010). Ding et al. (2010) and Gu et al. (2011) investigated the microstructure evolution during rolling process. Faraji et al. (2012) and Tang et al. (2012) studied the microstructure evolution during extruding process.

$316 \mathrm{LN}$ steel is widely used as a major material for nuclear main pipe. Its plasticity is low and deformation resistance is large. In past, extensive studies have been focused on creep behavior (Kim et al., 2008; Vodárek, 2011; Ganesan et al., 2013), crack (Schwartz et al., 2010; Kang et al., 2011; Zhang et al., 2013), weld characteristic (Kim et al., 2009), cutting performance (Ozcelik et al., 2011) and plasticity at high temperature (Hei et al., 2012). However, the microstructure evolution of multi-heat forging for $316 \mathrm{LN}$ steel has not been reported. Thus, the investigations of microstructure evolution of multi-heat forging are necessary to determine the forging technology of 316 LN steel.

In this study, the hot compressive tests and heat treatment tests of $316 \mathrm{LN}$ stainless steels were performed. The re-crystallization models and grain growth model were derived. The reliability and accuracy of these models were verified by comparing experimental values with simulated results. The influence of one-heat forging and three-heat forging on microstructure of 316 LN steel was studied by upsetting experiments and numerical simulation. Based on these, the reasonable forging technology of $316 \mathrm{LN}$ steel was determined.

\section{MICROSTRUCTURE EVOLUTION MODELS}

To simulate the microstructure evolution, the modeling of microstructure evolution process must be completed, namely, the quantitative relationships between material microstructure and deformation technology parameters are established (microstructure evolution models). Then, the models are integrated into the finite element software. The prediction of microstructure evolution is obtained by finite element calculation (Li et al., 2004).

The single-pass and double-pass compression experiments were conducted on Gleeble-1500 D thermal simulator. The heat treatment experiments were performed in heat treatment furnace. The $316 \mathrm{LN}$ steels with the dimensions of $\Phi 8 \times 12 \mathrm{~mm}$ were machined. The chemical composition (wt $\%$ ) of $316 \mathrm{LN}$ steel used in present study is $\mathrm{C} \leq 0.02 \%, \quad \mathrm{Mn} \leq 2.0 \%, \quad \mathrm{Si} \leq 0.7 \%$, $\mathrm{P} \leq 0.025 \%, \mathrm{~S} \leq 0.005 \%, \mathrm{Cr}=16-18 \%, \mathrm{Mo}=2-3 \%$, $\mathrm{Cu} \leq 0.1 \%$ and $\mathrm{N}=0.1-0.16 \%$. For heat treatment, the

\footnotetext{
Corresponding Author: Duan Xing-Wang, College of Materials Science and Engineering, Taiyuan University of Science and Technology, Shanxi, Taiyuan 030024, China

This work is licensed under a Creative Commons Attribution 4.0 International License (URL: http://creativecommons.org/licenses/by/4.0/).
} 
temperature range was $900-1200^{\circ} \mathrm{C}$ and the holding time range was 15-60 min and the initial grain size was about 22.5 and $75.5 \mu \mathrm{m}$. For single-pass compression, the temperature range was $900-1200^{\circ} \mathrm{C}$. The strain rate ranged from 0.005 to $0.5 \mathrm{~s}^{-1}$. The initial grain size was about 75 and $170 \mu \mathrm{m}$. For double-pass compression, the temperature range was $900-1150^{\circ} \mathrm{C}$. The strain rate ranged from 0.005 to $0.1 \mathrm{~s}^{-1}$. The initial grain size was about 75 and $170 \mu \mathrm{m}$. In the first pass, the strain was $0.1-0.5$. In the second pass, the strain was 0.05 . The interpass time was set according to deformation temperature. Based on Sellars model and Avrami equation, the models of re-crystallization and grain growth model were developed by regression of experimental data (Chen, 2010).

The models of dynamic re-crystallization are expressed as follows:

$$
\left\{\begin{array}{l}
\varepsilon_{p}=0.012 d_{0}{ }^{0.00037} \dot{\varepsilon}^{0.23}\left(\frac{45501}{R T}\right) \\
X_{d}=1-\exp \left[-1.778\left(\frac{\varepsilon-0.668 \varepsilon_{p}}{\varepsilon_{0.5}}\right)^{0.989}\right] \\
d_{d}=7.23 \times 10^{7} \dot{\varepsilon}^{0.00869} \exp \left(\frac{-183092}{R T}\right)
\end{array}\right.
$$

The models of meta-dynamic re-crystallization are expressed as follows:

$$
\left\{\begin{array}{l}
X_{m}=1-\exp \left[-0.693\left(\frac{t}{t_{0.5}}\right)^{0.88}\right] \\
t_{0.5}=8.62 \times 10^{-15} d_{0}^{1.76} \dot{\varepsilon}^{-0.21} \exp \left(\frac{279876}{R T}\right) \\
d_{m}=5.18 \times 10^{2} d_{0}^{0.293} \varepsilon^{-0.0386} \exp \left(\frac{-50669}{R T}\right)
\end{array}\right.
$$

The models of static re-crystallization are expressed as follows:

$$
\left\{\begin{array}{l}
X_{s}=1-\exp \left[-0.693\left(\frac{t}{t_{0.5}}\right)^{0.75}\right] \\
t_{0.5}=2.18 \times 10^{-16} d_{0}^{0.85} \varepsilon^{-1.419} \exp \left(\frac{353253}{R T}\right) \\
d_{s}=7.7 \times 10^{3} d_{0}^{0.4356} \varepsilon^{-0.317} \exp \left(\frac{-85446}{R T}\right)
\end{array}\right.
$$

The model of grain growth is expressed as follows:

$$
D_{\mathrm{t}}^{2.55}-D_{0}^{2.55}=1.95 \times 10^{13} \mathrm{t}_{\mathrm{h}} \exp \left(-\frac{307578}{R T}\right)
$$

where,

$\varepsilon_{p}=$ Peak strain $d_{0}=$ Initial grain size

$\dot{\varepsilon}=$ Strain rate

$\mathrm{R}=$ Molar gas constant

$\mathrm{T}=$ Thermodynamic temperature

$\dot{T}=$ Temperature rate

$X_{d}=$ Volume fraction of dynamic re-crystallization

$\varepsilon=$ Strain

$\varepsilon_{0.5}=$ Strain when re-crystallization volume fraction is $50 \%$

$d_{d}=$ Dynamic re-crystallization grain size

$X_{m}=$ Volume fraction of meta-dynamic recrystallization

$\mathrm{t}=$ Time of re-crystallization

$t_{0.5}=$ Time when volume fraction of re-crystallization is $50 \%$

$d_{m}=$ Meta-dynamic re-crystallization grain size

$X_{s}=$ Volume fraction of static re-crystallization

$d_{s}=$ Static re-crystallization grain size

$D_{0}=$ Initial average grain diameter

$D_{t}=$ Average grain diameter when holding time is $t_{h}$, $t_{h}$ is holding time

\section{FORGING EXPERIMENT AND NUMERICAL SIMULATION}

Forging experiment: The cylindrical specimens with $50 \mathrm{~mm}$ in diameter and $75 \mathrm{~mm}$ in height of $316 \mathrm{LN}$ steel were machined. The initial average grain size is about $213 \mu \mathrm{m}$. In order to study the influence of oneheat forging and three-heat forging on microstructure of 316 LN steel, the upsetting experiments were divided into one-heat upsetting and three-heat upsetting. The total deformation was same in both cases. The experiments were conducted in $2000 \mathrm{KN}$ hydraulic press. For one-heat upsetting, the specimen was deformed to the total deformation and then water quenched. For three-heat upsetting, the deformation of each heat upsetting was one-third of the total deformation and the specimen was treated with solution between heats. Finally, the specimen was water quenched. The upsetted specimen was divided into three different deformation regions (Fig. 1). I, II and III represent difficult deformation region, small deformation region and large deformation region, respectively. The microstructures of different regions of one-heat upsetting and three-heat upsetting are shown in Fig. 2.

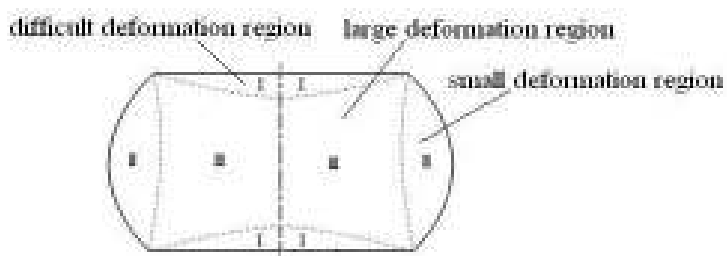

Fig. 1: Distribution diagram of deformation region 
Res. J. Appl. Sci. Eng. Technol., 7(5): 1012-1016, 2014

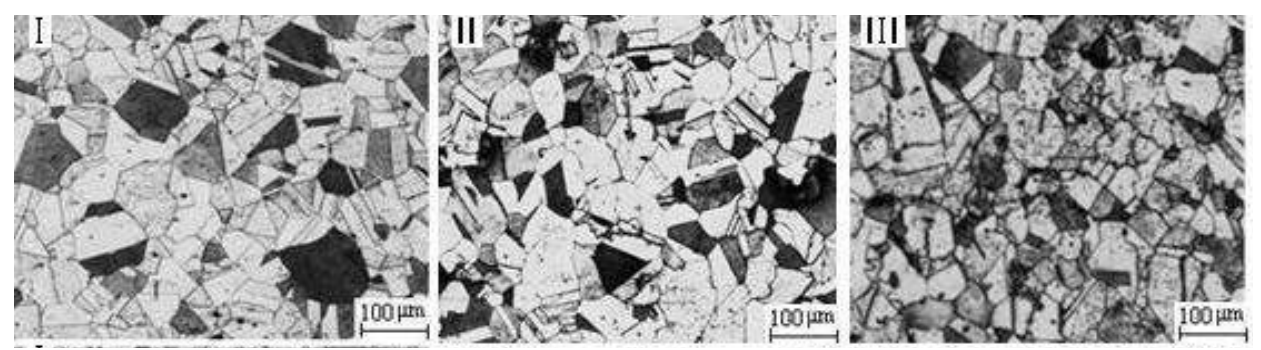

(a)

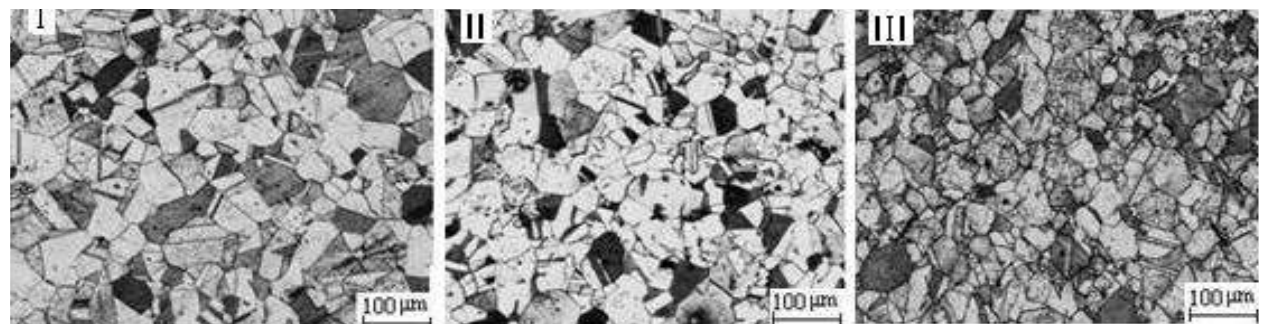

(b)

Fig. 2: The microstructures of different regions, (a) one-heat upsetting, (b) three-heat upsetting

Grain model - Average grain size (um)

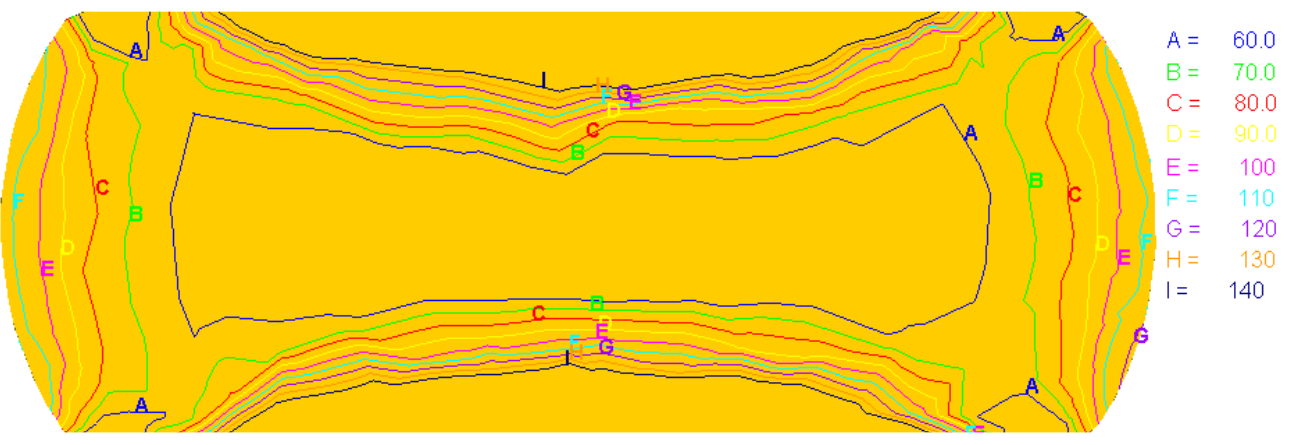

(a)

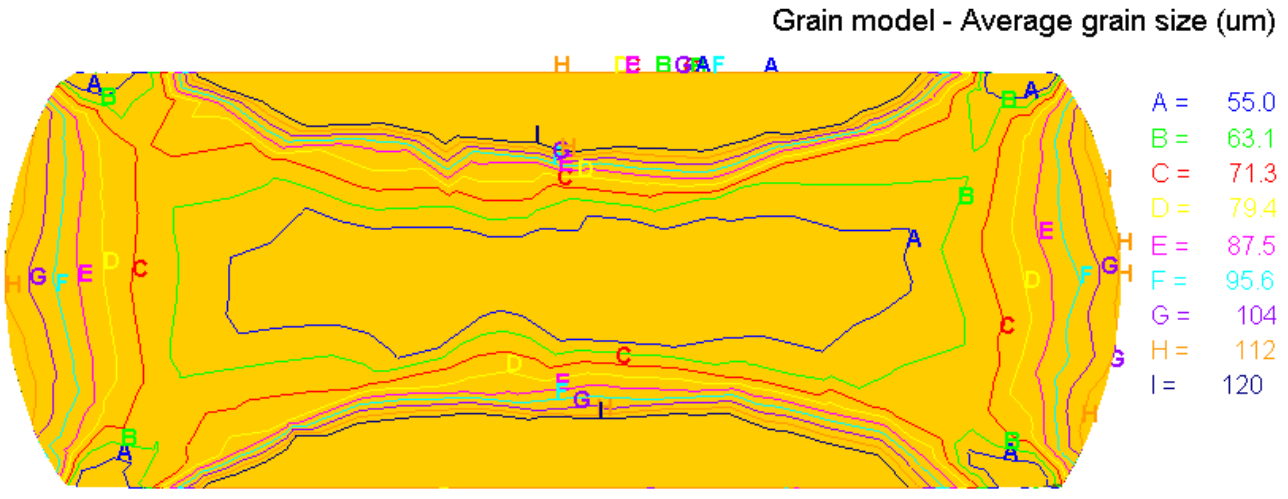

(b)

Fig. 3: The simulated average grain sizes, (a) for one-heat upsetting, (b) for three-heat upsetting 
Numerical simulation: The processes of one-heat upsetting and three-heat upsetting for $316 \mathrm{LN}$ steels were calculated by coupling finite element method with microstructure evolution models, respectively. The specimen size was $\Phi 50 \times 75 \mathrm{~mm}$. The initial grain size was same as that of upsetting experiment. According to the actual forging condition, the velocity of upper die was $10 \mathrm{~mm} / \mathrm{s}$. The friction coefficient at the die/work piece interface was 0.3 . The simulated average grain sizes of one-heat upsetting and three-heat upsetting are shown in Fig. 3.

\section{RESULTS AND DISCUSSION}

One fourth of upsetted specimen was used and divided into 8 different regions, as shown in Fig. 4.1 to 3 represents difficult deformation regions; 6,7 and 8 represent large deformation regions. The experimental average grain sizes are shown in Fig. 5. The simulated average grain sizes are shown in Fig. 6. The comparisons between experimental average grain sizes and simulated average grain sizes of 8 different regions for three-heat upsetting are shown in Fig. 7.

Figure 5 and 6 show that, in both upsetting experiment and numerical simulation, the grain uniformity of three-heat upsetting is much better that of one-heat upsetting and the average grain size of threeheat upsetting is smaller than that of one-heat upsetting. This is because that, for one-heat upsetting, only dynamic re-crystallization occurs and the grains become fine, but the non-uniformity of billets is not eliminated, the grain uniformity is not good. For threeheat upsetting, besides dynamic re-crystallization during upsetting process, due to solution treatment between heats, the meta-dynamic re-crystallization and static re-crystallization occur. Because the metadynamic re-crystallization and static re-crystallization can eliminate the distortion grains and elongated grains and the grains which have high storage energy, which make grains fine and uniform and the errors which be caused by non-uniformity of the initial grains are eliminated. Thus, the microstructures become more refinement and more uniform by three re-crystallization mechanisms and the mixed grains are also avoided. Therefore, the grain uniformity of three-heat upsetting is much better that of one-heat upsetting. The average grain size of three-heat upsetting is smaller than that of one-heat upsetting.

Figure 7 indicates that the simulated values of average grain size are in agreement with experimental values of average grain size, which shows that, the models of re-crystallization and grain growth model

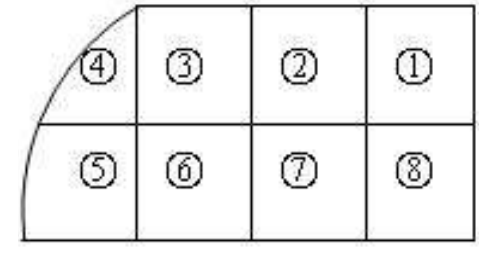

Fig. 4: Region lable

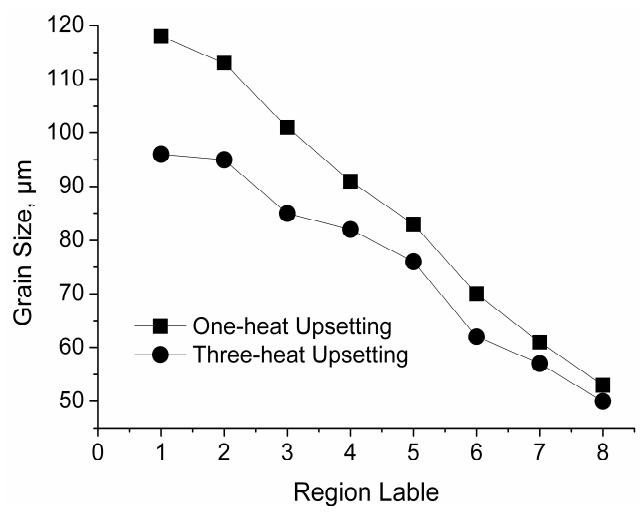

Fig. 5: The experimental average grain sizes

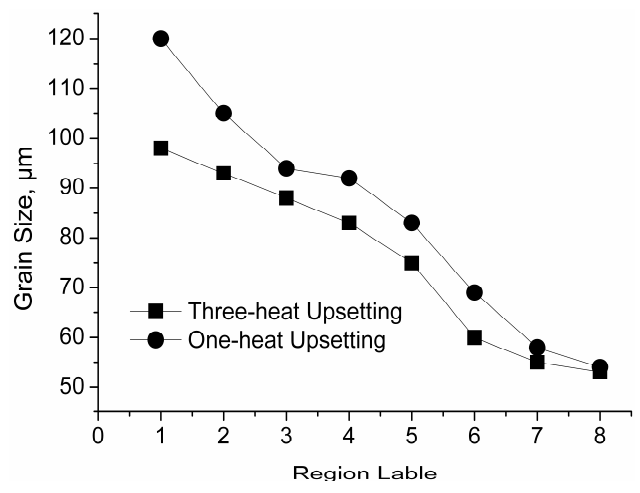

Fig. 6: The simulated average grain sizes

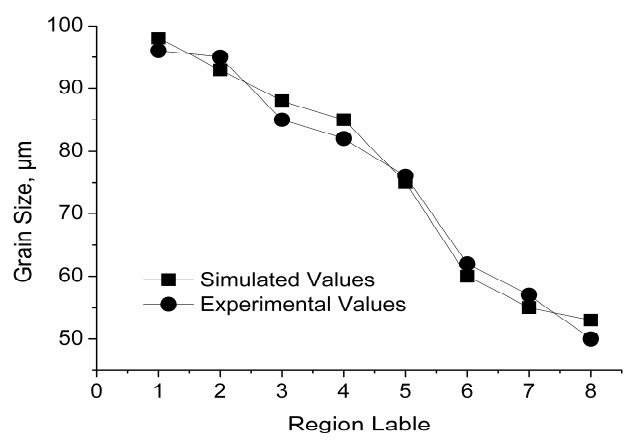

Fig. 7: The comparisons of experimental average grain sizes and simulated average grain sizes for three-heat upsetting 
developed of $316 \mathrm{LN}$ steels are reliable and the simulation accuracy is high. The numerical simulation technology can be employed to predict the multi-heat forging microstructure evolution of $316 \mathrm{LN}$ steel.

In view of the research above, the forging technology of multi-heat and little deformation should be adopted for $316 \mathrm{LN}$ steel forging.

\section{CONCLUSION}

The re-crystallization models and grain growth model of $316 \mathrm{LN}$ steels were derived. The reliability and accuracy of these models are verified by comparing simulated results with experimental values.

The forging technology of multi-heat and little deformation should be adopted for $316 \mathrm{LN}$ steel forging in order to improve the grain uniformity and refine the grain.

\section{ACKNOWLEDGMENT}

This study is supported by the major national science and technology project (No. 2009ZX04014062) and science and technology project of higher school in Shanxi province (No. 20111015) and outstanding innovation project of graduate in Shanxi province (No. 20103091).

\section{REFERENCES}

Chen, M.M., 2010. Study on experiment and simulation of grain evolution law of forging process for 316LN stainless steel. MS Thesis, Taiyuan University of Science and Technology, Shanxi.

Cho, J.R., H.S. Jeong, D.J. Cha, W.B. Bae and J.W. Lee, 2005. Prediction of microstructural evolution and recrystallization behaviors of hot working die steel by FEM. J. Mater. Process. Tech., 160: 1-8.

Ding, H.L., K. Hirai, T. Homma and S. Kamado, 2010. Numerical simulation for microstructure evolution in AM50 Mg alloy during hot rolling. Comp. Mater. Sci., 47: 919-925.

Faraji, G., M.M. Mashhadi and H.S. Kim, 2012. Microstructural evolution of UFG magnesium alloy produced by Accumulative Back Extrusion (ABE). Mater. Manuf. Process., 27: 267-272.

Ganesan, V., J. Ganesh Kumar, K. Laha and M.D. Mathew, 2013. Notch creep ruptures strength of $316 \mathrm{LN}$ SS and its variation with nitrogen content. Nucl. Eng. Des., 254: 179-184.

Gu, S.D., L.W. Zhang, C.X. Yue, J.H. Ruan, J.L. Zhang and H.J. Gao, 2011. Multi-field coupled numerical simulation of microstructure evolution during the hot rolling process of GCr15 steel rod. Comp. Mater. Sci., 50: 1951-1957.
He, W.W., J.S. Liu, Y.F. Guo, H.Q. Chen and H.G. Guo, 2010. Microstructure evolution of multiheats forging of $\mathrm{Mn} 18 \mathrm{Cr} 18 \mathrm{~N}$ retaining ring steel and numerical simulation. J. Plasticity Eng., 17(2): 45-49.

Hei, Z.G., X.W. Duan and J.S. Liu, 2012. Influence of temperature and strain rate on the high-temperature performances of $316 \mathrm{LN}$ steel. J. Taiyuan Univ. Sci. Tech., 33(4): 290-293.

Kang, H.J., S. Yang and H. Sun, 2011. Experimental study on stress corrosion cracking of 316LN. Nucl. Power Eng., 32(6): 101-114.

Kim, D.W., J.H. Chang and W.S. Ryu, 2008. Evaluation of the creep-fatigue damage mechanism of type $316 \mathrm{~L}$ and type $316 \mathrm{LN}$ stainless steel. Int. J. Pres. Ves. Pip., 85: 378-384.

Kim, H.C., K. Kim, Y.S. Lee, S.Y. Cho and H. Nakajima, 2009. Study on the weld characteristics of $316 \mathrm{LN}$ by magnetization measurement. J. Nucl. Mater., 386-388: 650-653.

Li, X.L., S.H. Chen and M.Q. Li, 2004. Modeling of microstructure evolution in metal hot plastic forming. China Mech. Eng., 15(1): 86-90.

Lin, Y.C. and M.S. Chen, 2009. Numerical simulation and experimental verification of microstructure evolution in a three-dimensional hot upsetting process. J. Mater. Process. Tech., 209: 4578-4583.

Ma, Q., Z.Q. Lin and Z.Q. Yu, 2007. A numerical simulation of microstructure evolution of IN718 alloy during multi-step forging. J. Shanghai Jiaotong Univ., 41(4): 629-633.

Ozcelik, B., E. Kuram and B.T. Simsek, 2011. Comparison of dry and wet end milling of AISI 316 stainless steel. Mater. Manuf. Process., 26: 1041-1049.

Schwartz, J., O. Fandeur and C. Rey, 2010. Fatigue crack initiation modeling of $316 \mathrm{LN}$ steel based on non local plasticity theory. Proc. Eng., 2: 1353-1362.

Tang, C.P., L. Yang, D. Feng, Y.L. Deng and X.M. Zhang, 2012. Investigation on microstructure and mechanical properties of a Mg-Gd-Y-Zr alloy plate. Mater. Manuf. Process., 27: 609-613.

Vodárek, V., 2011. Creep behavior and microstructural evolution in AISI $316 \mathrm{LN}+\mathrm{Nb}$ steels at $650^{\circ} \mathrm{C}$. Mater. Sci. Eng. A, 528: 4232-4238.

Zhang, X.Z., Y.S. Zhang, Y.J. Li and J.S. Liu, 2013. Cracking initiation mechanism of 316LN stainless steel in the process of the hot deformation. Mater. Sci. Eng. A, 559: 301-306. 